\title{
Identification and Preservation of External Branch of Superior Laryngeal Nerve in Thyroidectomy
}

\author{
Poorva K Athavale, Bhagyashree D Bokare, Vipin R Ekhar, Devendra Meghraj Mahore
}

\begin{abstract}
The basic principle of head and neck surgery is based on the identification and preservation of important structures, rather than avoidance. This principle is also applicable to identification and preservation of external branch of the superior laryngeal nerve (EBSLN) as a standard routine in all thyroid surgeries. During thyroid surgery, the EBSLN is clearly at risk due to its close proximity to the superior thyroid artery (STA) and its branches that need to be ligated during dissection of the superior pole of the thyroid gland. Injury is detrimental to the patient by causing paralysis of the cricothyroid muscle which is the main tensor and pitch controlling mechanism of the vocal folds. Injury to the EBSLN during surgery can result in the voice changes, loss of upper range and easy fatigability of voice, the severity of which varies according to the vocal demand of the patient.

Total 45 cases of thyroid swellings were treated with surgery, in the Department of ENT at a tertiary care hospital during the period from 1st October 2009 to 30th October 2010. Hemithyroidectomy was the most common operative procedure implemented in 24 patients $(53.33 \%)$ in which right sided was common. Next common procedure performed was that of total thyroidectomy in 14 patients (31.11\%). Four patients underwent total thyroidectomy with neck dissection. The position of EBSLN was classified according the Cernea et al classification. In our study we found the EBSLN to be type I in $46.66 \%$, type Ila in $73.33 \%$ and type $\mathrm{llb}$ in $02.22 \%$. The anatomical landmark taken into consideration to identify EBSLN was the Joll's triangle with its relation to the superior pole of the thyroid gland and STA.
\end{abstract}

Keywords: External branch of the superior laryngeal nerve, Thyroidectomy, Professional voice.

How to cite this article: Athavale PK, Bokare BD, Ekhar VR, Mahore DM. Identification and Preservation of External Branch of Superior Laryngeal Nerve in Thyroidectomy. Int J Phonosurg Laryngol 2013;3(2):39-41.

Source of support: Nil

Conflict of interest: None declared

\section{INTRODUCTION}

Delicate and deliberate surgical technique and careful attention to details are required to prevent common complications of thyroid resections. Thyroidectomy is a common operation and it is recognized that damage to the external branch of the superior laryngeal nerve (EBSLN) is one of the concerns of this surgery. Initially overshadowed by the importance of recurrent laryngeal nerve, the clinical importance of the EBSLN has been highlighted of late. The EBSLN supplies the cricothyroid muscle which is the principal tensor of the vocal fold and its injury leads to inability to raise pitch, reduced volume and easy fatigability.
The basic principle of head and neck surgery is based on the identification and preservation, rather than avoidance of important structures. This principle is also applicable to identification and preservation of EBSLN as a standard in all thyroid surgeries. The EBSLN is intimately associated with the superior thyroid artery (STA) in relation to the superior pole of the thyroid gland, rendering it vulnerable to injury during dissection in thyroidectomy.

This study was undertaken to study the topographical relationship of EBSLN with the superior thyroid vessels and the superior pole of thyroid gland. The EBSLN was classified according to Cernea et al classification ${ }^{1}$ (Fig. 1) (Table 1).

The objective of the present study was to describe the anatomical relations of the ELN, STA and tip of the superior pole of the thyroid gland, particularly the distance from the superior pole at which ELN and STA the cross each other in the area considered 'dangerous' area while ligating the vessels during thyroid surgery, individual ligation of all the branches was stressed.

\section{MATERIALS AND METHODS}

Total 45 cases of thyroid swellings were treated in the department of ENT at Tertiary care hospital during the period from 1 st October 2009 to 31 st October 2010. The study was of 1 year duration and the following criteria were made for selection of patients.

\section{Inclusion Criteria}

All patients with thyroid swellings, nodular or cystic, benign or malignant who underwent thyroid surgery. Patients were either euthyroid or if with hypothyroidism/hyperthyroidism taken for surgery after achieving euthyroid status with medical treatment.

\section{Exclusion Criteria}

Previous laryngeal or thyroid surgery, previous neck irradiation and any other cervical exploration.

Once the patient was selected for the study, an informed written consent was taken and a detailed history and clinical examination of the patient were recorded according to a proforma. Investigations done included routine hematology, radiograph of the neck and chest, high resolution ultrasonography of the neck, guided fine needle 


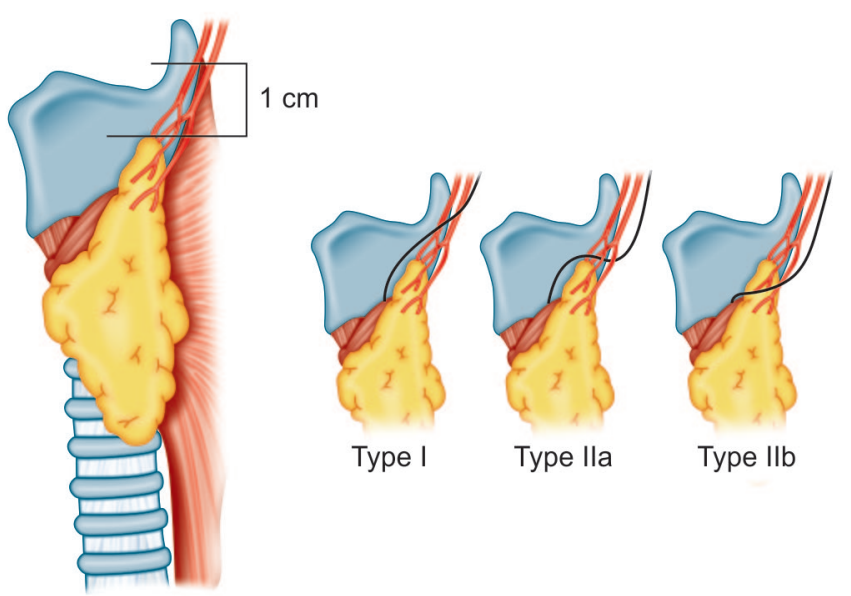

Fig. 1: Cernea et al classification

aspiration cytology, thyroid profile and as and when needed computed tomographic (CT) scan of the neck, chest and head. According to the investigations, diagnosis was established and patients underwent the required surgical procedures. Various surgeries were done, included hemithyroidectomy, subtotal thyroidectomy and total thyroidectomy with/without neck dissection. Intraoperative findings were noted in details with respect to consistency of the involved thyroid gland, infiltration into surrounding structures and presence/absence of lymph nodes.

Meticulous dissection of the upper pole of the thyroid is key to the positive identification of the EBSLN. Joll's triangle was taken as landmark for the identification of the nerve and the superior pole vessels and the loose areolar tissue surrounding them were not dissected until the EBSLN is explored. The basic principle followed was that the nerve was identified prior to ligation of the superior vascular pedicle, and the nerve and cricothyroid muscle were protected throughout the procedure.

The position of the nerve was determined according to Cernea et al classification. The vocal cord function was assessed preoperatively and postoperatively by Hopkins rod examination. A regular follow-up of all the patients as regards the complications of surgery was done.

\section{RESULTS}

Total of 45 patients were evaluated during the study period. Maximum number of patients, i.e. 24 patients, underwent hemithyroidectomy. Eighteen patients underwent total thyroidectomy with/without neck dissection and the remaining three patients underwent subtotal thyroidectomy.

As far as gender distribution was concerned, eight were men and 37 were women. The pitch of voice gets lowered due to injury to EBSLN. This can affect women much more than men. The EBSLN was identified in all the patients irrespective of the etiology and type of thyroid disease. Of the 18 patients who underwent total thyroidectomy, 13 were for malignant lesions.

Total of 55 EBSLN were identified out of the 63 upper poles dissected. Eight nerves could not be identified, mostly because of bleeding during the dissection.

We found that type IIa, i.e. EBSLN situated less than $1 \mathrm{~cm}$ from the upper pole was the most common type observed in $60 \%$ of our patients (Table 2). Type I, i.e. the nerve lying more than $1 \mathrm{~cm}$ from the upper pole was the next most common seen in $38.18 \%$ and type IIb was least common seen in $1.81 \%$. No significant relationships existed between; the type of the nerve, gender, and age, nor was any symmetry noted with regard to the location of the external branch of the SLN on two sides in the same subject.

\section{DISCUSSION}

Voice change is a morbidity associated with thyroid surgery due to failure to identify the EBSLN and its subsequent injury during dissection of the superior thyroid pole. It is the combination of reduced range of pitch, volume and voice fatigability which is seen after injury to EBSLN that affects patients-females, professional voice users and young

\begin{tabular}{ll} 
& Table 1: Cernea et al classification \\
\hline Type I & Crosses STA more $>1 \mathrm{~cm}$ above the upper pole \\
Type Ila & Crosses STA more $<1 \mathrm{~cm}$ above the upper pole \\
Type Ilb & $\begin{array}{l}\text { Descends dorsal to artery and crosses STA branches } \\
\text { immediately above upper pole }\end{array}$ \\
\hline
\end{tabular}

Table 2: Location of EBSLN with respect to the superior pole in 45 patients of study

\begin{tabular}{|c|c|c|c|c|c|c|c|}
\hline \multirow[t]{2}{*}{ Type of surgery } & \multirow[t]{2}{*}{$\begin{array}{l}\text { Location of } \\
\text { EBSLN }\end{array}$} & \multicolumn{2}{|c|}{ Hemithyroidectomy (24) } & \multicolumn{2}{|c|}{$\begin{array}{l}\text { Total thyroidectomy } \pm \\
\text { neck dissection (18) }\end{array}$} & \multicolumn{2}{|c|}{$\begin{array}{l}\text { Subtotal } \\
\text { thyroidectomy (3) }\end{array}$} \\
\hline & & Right & Left & Right & Left & Right & Left \\
\hline \multicolumn{2}{|c|}{ More than $1 \mathrm{~cm}$ (Type I) } & 04 & 04 & 06 & 06 & 00 & 01 \\
\hline \multicolumn{2}{|c|}{ Less than $1 \mathrm{~cm}$ (Type Ila) } & 11 & 05 & 09 & 07 & 01 & 00 \\
\hline \multicolumn{2}{|c|}{ Under cover of the gland (Type IIb) } & 00 & 00 & 00 & 00 & 01 & 00 \\
\hline
\end{tabular}




\begin{tabular}{lllll}
\hline \multicolumn{5}{c}{ Table 3: Our study compared to previous studies } \\
\hline Study & Type I & Type Ila & Type Ilb & $\begin{array}{l}\text { Not } \\
\text { seen }\end{array}$ \\
\hline Present study & $38.18 \%$ & $60 \%$ & $01.81 \%$ & - \\
Aina EN et al & $17.30 \%$ & $56 \%$ & $26.7 \%$ & - \\
Ozlugedik S et al & $22.50 \%$ & $60 \%$ & $17.5 \%$ & - \\
Mishra AK et al & $28.20 \%$ & $53.54 \%$ & $08 \%$ & - \\
Pradeep PV et al & $70.7 \%$ & $17.9 \%$ & $8 \%$ & $3.4 \%$ \\
Study at Nellore & $72.3 \%$ & $15.7 \%$ & $6.3 \%$ & $5.4 \%$ \\
\hline
\end{tabular}

patients are affected most. Meticulous dissection in the region of the upper pole of the thyroid is most important for the proper identification of the EBSLN. The nerve can be identified in most cases irrespective of the pathology and size of the lesion, even malignancy usually does not interfere in the identification of the nerve. Joll's triangle (sternothyroid laryngeal triangle) is an important landmark for the identification of EBSLN. ${ }^{2}$ It is formed laterally by the upper pole of the thyroid gland and vessels, superiorly by the attachment of the strap muscles and deep investing layer of fascia to the thyroid and medially by the midline. Its floor is cricothyroid, and its content is EBSLN. ${ }^{2}$ It is important to positively identify the nerve as it crosses this relatively avascular space before ligating the vessels, especially in the type IIb cases, where the nerve is at risk of injury during ligation of the vessels close to the gland. ${ }^{3}$ Although type IIb is rare, it is most dangerous of the three, and is considered to be most 'at risk' during dissection. ${ }^{1}$ We need to be aware of this type and be cautious during dissection. Individual ligation of superior thyroid vessels, artery and vein, and their branches will reduce the risk of injury to nerve. ${ }^{3}$

A majority of the studies on the laryngeal nerves are on cadavers. ${ }^{6,7}$ Although there have been studies reporting the surgical anatomy of the EBSLN from the west, only a few Indian studies have been reported. ${ }^{5,7}$ This study aims to record the topographical relationship of the EBSLN with the superior thyroid pole and STA as encountered in cases during surgery in our patients.

Our results are comparable to other studies (Table 3). In all the studies, type IIa was the most common type. ${ }^{4-7}$ However, in our study the incidence of type IIb is less compared to other studies. Comparison with other Indian studies, suggest a variation even within the same ethnic population.

\section{CONCLUSION}

The clinical importance of the EBSLN had been largely overshadowed by emphasis on the recurrent laryngeal nerve in the past as morbidity due to thyroid surgery decreased dramatically, injury of the EBSLN leading to voice change, received increasing attention over the years. In today's times, with its increasing stress on verbal communication and an ever increasing segment of professional voice users, voice has suddenly gained far more priority than in the past. Quality of voice is an important issue for every single patient that we deal with not just professional voice users and performing arts professionals. Intentionally identifying the EBSLN, along with the recurrent laryngeal nerve is now considered mandatory in thyroid surgery and one must be well versed with its surgical anatomy and anatomical variations associated with it and prevent its injury. Cernea's classification is of value in identification and preservation and documentation of EBSLN during thyroid surgery in a high percentage of cases.

\section{REFERENCES}

1. Cernea CR, Nishio S, Hojaij FC. Identification of the EBSLN in large goitres. Am J Otol 1995;16:307-311.

2. Gray H. Anatomy of the Human Body. Philadelphia: Lea \& Febiger, 1918; p. 910-913

3. Friedman M, LoSavio P, Ibrahim H. Superior laryngeal nerve identification and preservation in thyroidectomy. Arch Otolaryngol Head Neck Surg 2002;128:296-303.

4. Aina EN, Hisham AN. External laryngeal nerve in thyroid surgery: recognition and surgical implications. ANZ J Surg 2001;71: 212-214.

5. Mishra AK, Temadari H, Singh N, Mishra SK, Agarwal A. The external laryngeal nerve in thyroid surgery: the 'no more neglected' nerve. Indian J Med Sci 2007;61:3-8.

6. Ozlugedik S, Acar HI, Apaydin N, Tekdemir I, Elhan A, Comert A. Surgical anatomy of the external branch of the superior laryngeal nerve. Clin Anat 2007 May;20(4):387-391.

7. Pradeep PV, Jayashree B, Harshita SS. A closer look at laryngeal nerves during thyroid surgery: a descriptive study of 584 nerves. Anat Res Int 2012;2012:490390.

\section{ABOUT THE AUTHORS}

\section{Poorva K Athavale}

Junior Resident, Department of ENT, Government Medical College Nagpur, Maharashtra, India

\section{Bhagyashree D Bokare}

Associate Professor, Department of ENT, Government Medical College, Nagpur, Maharashtra, India

\section{Vipin R Ekhar}

Assistant Professor, Department of ENT, Government Medical College, Nagpur, Maharashtra, India

\section{Devendra Meghraj Mahore (Corresponding Author)}

Associate Professor, Department of ENT, Government Medical College Nagpur, Maharashtra, India, Phone: 07122220554, e-mail: mahoredm@ gmail.com 